Boise State University

ScholarWorks

3-1-1997

Corticosterone and the Stress Response in Young Western Screech-Owls: Effects of Captivity, Gender, and Activity Period

Alfred M. Dufty Jr.

Boise State University

James R. Belthoff

Boise State University 


\section{Corticosterone and the Stress Response in Young Western Screech- Owls: Effects of Captivity, Gender, and Activity Period}

\author{
Alfred M. Dufty, Jr. \\ James R. Belthoff \\ Department of Biology, Boise State University, \\ Boise, Idaho 83725
}

Accepted by G.K.S. 8/12/96

\begin{abstract}
We used a standard handling protocol to examine the stress response of captive young western screech-owls during their active (nighttime) and inactive (daytime) periods and to compare the stress responses of captive and free-living owls. Circulating corticosterone levels were significantly higher during the inactive period than in the active period in this nocturnal species. This suggests that the daily pattern of corticosterone secretion is reversed in nocturnal birds and is correlated with activity period rather than with the light/dark cycle. Young (ca. 4-5 mo old) screech-owls of both sexes showed increases in plasma corticosterone up to $30 \mathrm{~min}$ after capture, followed by significant decreases at $60 \mathrm{~min}$. This pattern is similar to those of other species of birds examined previously, except that decreases in corticosterone at $60 \mathrm{~min}$ rarely have been observed. Such decreases may be the result of physiological differences between adult and young birds, habituation to handling in captive birds, or the effects of body condition. Corticosterone levels and the response to capture and handling were comparable in captive and free-living owls, which suggests that the captive owls were not subjected to chronically high levels of stress.
\end{abstract}

\section{Introduction}

Adrenocortical hormones are released in response to stressful stimuli in all vertebrates, including birds (e.g., Harvey et al. 1984; Smith et al. 1994). The release of corticosterone, the primary avian adrenocorticoid, into the bloodstream facilitates many of the physiological adjustments that enable birds to restore homeostasis in the face of disruptive events (see, e.g.,

Physiological Zoology 70(2):143-149. 1997. (C) 1997 by The University of Chicago. All rights reserved. 0031-935X/97/7002-9608\$02.00
Harvey et al. 1984; Cherel et al. 1988; Gray et al. 1990; Buttemer et al. 1991). Adrenal activity also produces behavioral changes in birds that may contribute to the amelioration of stressful situations (Wingfield 1994). For example, corticosterone stimulates increased locomotor and foraging activity (Gray et al. 1990; Astheimer et al. 1992) and reduced reproductive activity (Wingfield 1984, 1994). These behavioral responses direct birds' efforts toward energy acquisition and survival and away from energetically costly behaviors, such as breeding.

The development of a standardized capture and handling stress protocol (Wingfield et al. 1992) has allowed comparison of stress responses among unrelated avian species experiencing different ecological and seasonal conditions (see, e.g., Wingfield et al. [1995] and references therein). Consequently, the interplay among the physiological and ecological factors that produce the stress response in breeding and nonbreeding adult birds is being examined closely (Wingfield 1994; Wingfield et al. 1995).

One area that has not been explored systematically is the effect of stress on the adrenal response of young birds. The hypothalamic-pituitary-adrenocortical axis may not be fully mature at hatching. For example, in domestic fowl (Gallus domesticus), the adrenal glands increase their responsiveness to adrenocorticotropic hormone during the first several months of life, as corticosterone secretion develops into the adult-like pattern (Webb and Mashaly 1985). Thus, it is important to determine if newly independent juvenile birds of either or both sexes respond to stress in a manner similar to adults.

Furthermore, previous investigations of avian stress responses have been limited to the birds' active periods, and all avian species heretofore examined are active during the daytime. Because of this, it is not clear if the rate of onset or magnitude of the stress response differs between the active and inactive periods in birds. In addition, there is often a daily rhythm in plasma corticosterone secretion (see, e.g., Boissin and Assenmacher 1971; Joseph and Meier 1973; Beuving and Vonder 1977; but see Marra et al. 1995), and maximal corticosterone levels occur during the inactive (nocturnal) period. As a result, it is not known if elevated corticosterone secretion is a function of nighttime or of inactivity. Examination of corticosterone secretion in species of nocturnal birds would differentiate between the two.

During their active period, birds with already elevated corticosterone levels do not show additional responsiveness when subjected to the capture and handling stress protocol (Smith 
et al. 1994). Previous studies indicate that captivity may be one factor that results in elevated corticosterone levels. For instance, Marra et al. (1995) found that secretory profiles of corticosterone differed significantly between captive and freeliving individuals in two species of sparrows in the genus Zonotrichia. Captive individuals exhibited levels between two and three times higher than those of free-living birds despite the fact that they had the opportunity to acclimate to captivity for more than 1 mo prior to sampling. This begs the question of whether captive birds respond to capture and handling stress with an adrenocortical response.

Our objectives in the present study were to (1) examine the capture and handling stress response in young birds of both sexes, (2) determine if and how the stress response differs during the active and inactive periods, and (3) examine differences in corticosterone titers and the stress response in captive and free-living birds.

\section{Material and Methods}

\section{Study Species}

In this study we examined the stress response in captive and free-living young western screech-owls (Otus kennicottii). These small (ca. $250 \mathrm{~g}$ ) nocturnal owls are common in lowelevation forests, riparian woodlands, and suburban areas throughout the western United States (Johnsgard 1988). They are nonmigratory, territorial, and secondary cavity nesters, and they breed in both natural cavities and artificial nest boxes (J. R. Belthoff, personal observations). In southwestern Idaho, where our studies were conducted, young owls hatch in midApril and fledge approximately $28 \mathrm{~d}$ later. Following a $6-10-w \mathrm{k}$ dependency period, young owls disperse to winter territories beginning in late June and continuing through mid-August, although most individuals disperse in mid-July (Belthoff and Dufty 1995; E. A. Ellsworth and J. R. Belthoff, unpublished data). Once young have settled, they defend the area from conspecifics and commence breeding the following spring if resources (e.g., mates, nest cavities, cover, food) are adequate on the territory.

\section{Laboratory Samples}

During the period of May 12-25, 1995, we collected 12 nestling western screech-owls and transported them to the animal care facility on the campus of Boise State University. The nests from which owls were collected ( $n=5)$ were in artificial nest boxes mounted along the Snake River in Elmore and Owyhee Counties and along the Boise River in Ada County, Idaho. On the basis of development at the time of collection, all owls appeared to be about 23-24 d old, or about 1 wk from leaving the nest box.

In captivity, owls were kept in wire-mesh cages measuring approximately $0.5 \mathrm{~m} \times 0.5 \mathrm{~m} \times 1.0 \mathrm{~m}$, which were placed in individual sound-attenuating isolation chambers. In the front of each chamber was a clear plastic window (ca. $29 \mathrm{~cm} \times 45$ $\mathrm{cm})$. Once in the chambers, owls could not interact visually or vocally. We provided owls with laboratory mice, day-old chickens, and water ad lib. The owls remained undisturbed except for feeding and cage maintenance, which required less than $1 \mathrm{~h}$ each day. Once each day we also removed each owl from its cage to read its backpack-mounted pedometer (Micronta Mini-Jog Mate, catalog no. 63-667, Radio Shack), which recorded locomotor activity as part of another study (see Ritchison et al. [1992] and Belthoff and Dufty [1995] for other details on pedometers and their use). Thus, each bird also was handled by one of the investigators for approximately $1 \mathrm{~min}$ each day during its captivity. Light entered the animals' room through a large $(12 \mathrm{~m} \times 1.5 \mathrm{~m})$, south-facing set of windows, which allowed the owls to experience the natural photoperiod. All owls remained in good heath while in captivity.

Between August 25 and September 12, 1995, we performed the capture and handling stress protocol on 4-5-mo-old captive owls during each of two time periods, termed active and inactive. For western screech-owls, the active period corresponds to nighttime and the inactive period to daytime, which is opposite to diurnal species. For the active period, samples were collected $1 \mathrm{~h}$ after dark, at approximately 2230-2300 hours. For the inactive period, samples were collected between 1300 and 1500 hours. Owls were randomly assigned to one of two treatment sequences such that six owls initially were sampled during the active period and the other six initially were sampled during the inactive period. An average of $6 \mathrm{~d}$ was allowed to pass before taking blood during the second period. The owls weighed an average of $213 \mathrm{~g}$ (range: 174-281 g) when this study began. Prior to this study, the 12 owls had been bled on a weekly basis (beginning 1 wk after capture; 600 $\mu \mathrm{L}$ of whole blood removed per sample) as part of another study to assess circulating hormones in relation to locomotor activity patterns and dispersal (see Belthoff and Dufty 1995).

To assess the effects of handling stress on circulating corticosterone levels during active and inactive periods, five blood samples were obtained from each owl during each activity period. These samples were obtained 1,5, 10,30, and $60 \mathrm{~min}$ following removal of the owl from its home cage (Wingfield et al. 1992). Blood samples were collected by puncture of the brachial vein with a 26-gauge needle. Whole blood was collected into between one and three heparinized microhematocrit tubes. These were kept on ice until centrifuged (within $1 \mathrm{~h}$ ) at $8,000 \mathrm{rpm}$ for $3 \mathrm{~min}$. Plasma was harvested and frozen at $-20^{\circ} \mathrm{C}$ until the hormone assay was performed. Between sampling periods, owls were held in cotton-mesh sacks and left undisturbed.

The sex of young screech-owls generally cannot be determined accurately on the basis of morphological or plumage characteristics alone (J. R. Belthoff, personal observations). 
Therefore, after we removed the plasma for radioimmunoassay, we provided the remaining hematocrit samples to a commercial laboratory (Zoogen, Davis, Calif.) for analysis. The laboratory used a heterologous sex-specific probe on DNA isolated from the owl blood to determine the gender of the captive owls.

The study sample consisted of eight males and four females. Following exercise in flight cages, during which time captive owls learned to hunt live mice, the owls were released in accordance with agency permit specifications.

\section{Field Samples}

We also obtained blood samples (ca. $600 \mu \mathrm{L}$ whole blood) from free-living western screech-owls and compared the pattern of corticosterone secretion and the range of plasma corticosterone values with those of captive owls. Fledgling screech-owls ( $n=11$ ) were captured at night (range: $2150-2335$ hours) from June 6 to July 10, 1994, and on June 22, 1995, with mist nets placed within their home ranges. These owls were 2-3 mo younger than the captive birds and had not yet dispersed; some were still dependent on adults for provisioning. Some birds were lured to the nets by broadcasting the calls of adult screech-owls. Ten of the birds previously had been captured as nestlings, bled as described above, given numbered aluminum leg bands, and affixed with backpack radio transmitters (Model SOPB-2190, Wildlife Materials, Carbondale, Ill.; see Belthoff and Ritchison [1989, 1990] for description of transmitters and attachment methods). These birds were sexed as described earlier, and the sample consisted of six males and four females. The remaining fledgling, of unknown sex, had not been captured previously.

Unlike in the stress protocol used for captive birds, when free-flying young were captured, we collected only one blood sample per bird. We recorded the length of time from capture to completion of the sampling procedure for all birds. Six blood samples were collected in $5 \mathrm{~min}$ or less, four in 5$10 \mathrm{~min}$, and one in $30 \mathrm{~min}$. Blood was placed in $1.5-\mathrm{mL}$ microcentrifuge tubes, which were kept on ice for $2-3 \mathrm{~h}$, transported to the laboratory, and centrifuged. The plasma and hematocrit were separated and stored as described previously.

\section{Corticosterone Radioimmunoassay}

Plasma corticosterone levels in captive owls were measured with the protocol described by Wingfield et al. (1992). Plasma volumes were $20-50 \mu \mathrm{L}$. Approximately $2,000 \mathrm{cpm}$ of tritiated corticosterone was added to each sample, along with $300 \mu \mathrm{L}$ of distilled water, and samples were refrigerated $\left(4^{\circ} \mathrm{C}\right)$ for $3 \mathrm{~h}$. Five milliliters of freshly distilled dichloromethane was added to each sample to extract corticosterone, and samples were refrigerated overnight. The lower (organic) phase was removed and dried in a water bath $\left(40^{\circ} \mathrm{C}\right)$ under nitrogen gas, and samples were reconstituted with $550 \mu \mathrm{L}$ of buffer. Duplicate assay tubes received $200-\mu \mathrm{L}$ aliquots for each sample. An additional $100-\mu \mathrm{L}$ aliquot was added to a scintillation vial (along with $4.5 \mathrm{~mL}$ of scintillant), which enabled us to determine recovery values for the extraction process. Intra- and interassay coefficients of variation were $1 \%-13 \%$.

\section{Experimental Design and Statistical Analyses}

In captive owls, we examined the effects of sex, activity period, and sampling time on circulating corticosterone using a threefactor mixed factorial design (Zolman 1993). In this design, sex was a between-group factor, and both time and activity period represented within-subjects factors or repeated measures. Using ANOVA, we examined the main effects and their interactions following log transformation of the data. If significant effects were detected, we calculated least squares means and compared them using pairwise $t$-tests. Methodological differences (i.e., collection of single vs. multiple blood samples) preclude any direct comparison of free-living and captive screech-owls. However, for field samples we used the nonparametric Mann-Whitney $U$-test to compare corticosterone levels in samples taken after $5 \mathrm{~min}$ or less of handling to those with relatively longer handling times (5-10 min). Finally, all data are presented as mean \pm standard error, and rejection levels were set at $P=0.05$.

\section{Results}

\section{Captive Screech-Owls}

The pattern of the adrenocortical response of captive young screech-owls to handling stress is shown in Figure 1. One bird (male 064) did not exhibit an adrenocortical response to handling stress in either time period. Results for this bird are shown separately in Figure 1 and are not included in the analyses. We detected no effect of sex on the pattern of corticosterone secretion (overall for males: $27.3 \pm 1.56 \mathrm{ng} / \mathrm{mL}, n=70$ samples from seven males; overall for females: $27.5 \pm 2.06 \mathrm{ng} / \mathrm{mL}, n$ $=40$ samples from four females; Fig. 1A), and sex did not interact with any of the other factors in the model. There was an effect of activity period on the adrenocortical response (Table 1); samples obtained during the inactive (daytime) period (overall for day: $29.5 \pm 1.82 \mathrm{ng} / \mathrm{mL}, n=55$ samples from 11 birds) exhibited significantly higher corticosterone levels than those obtained during the active (nighttime) period (overall for night: $25.3 \pm 1.82 \mathrm{ng} / \mathrm{mL}, n=55$ samples from 11 birds; Fig. 1B). The lack of a significant interaction between time and activity period (Table 1) indicates that the pattern of corticosterone secretion was similar during day and night, even though absolute corticosterone levels were higher during the day.

For the remaining 11 birds included in the analysis, basal corticosterone levels (i.e., those collected after only $1 \mathrm{~min}$ of 

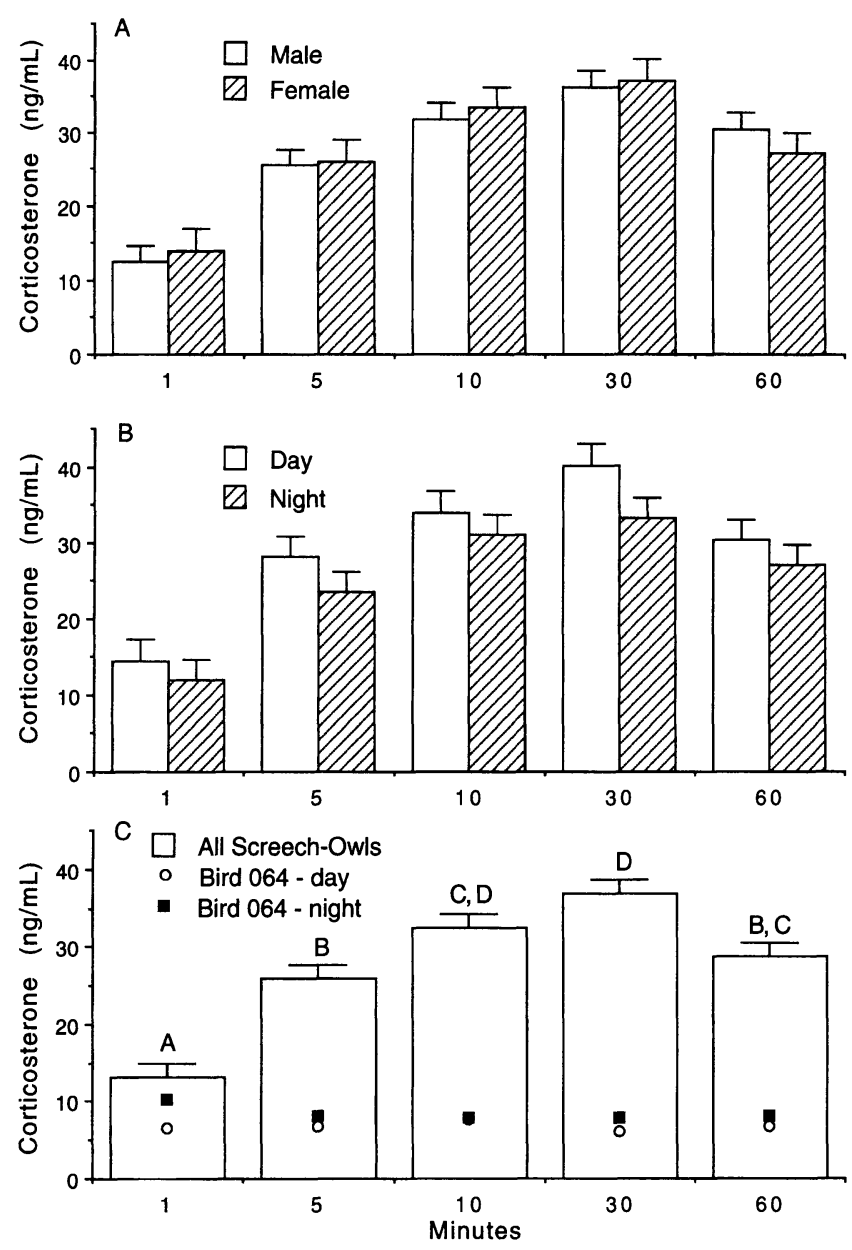

Figure 1. Circulating corticosterone levels (mean $\pm \mathrm{SE}$ ) of captive juvenile western screech-owls across sampling time periods by $A$, sex (four females, seven males); $B$, activity period; and $C$, all sexes and activity periods. Panel $C$ also presents the corticosterone values of one male (064) that did not show a stress response and was excluded from subsequent analyses. None of the pairwise comparisons in $A$ or $B$ are significant at the $P<0.05$ level. In $C$, bars labeled with the same letter do not differ significantly.

handling) averaged $13.2 \pm 1.82 \mathrm{ng} / \mathrm{mL}$, but time had a significant $(P<0.001)$ effect on plasma corticosterone levels (Fig. $1 C)$. Plasma corticosterone titers increased significantly between the 1and 5-min samples and again between the 5- and 10-min samples. Although the mean corticosterone level continued to increase until $30 \mathrm{~min}$, the difference between the 10 - and 30 -min samples was not significant. However, by $60 \mathrm{~min}$ there was a significant decline in the mean plasma corticosterone value compared with that of the 30 -min samples. Finally, there were no significant interactions between sex and time or between activity period and time, nor was there a three-way interaction among sex, activity period, and time (Table 1).

\section{Free-Living Screech-Owls}

There also was an effect of time on the pattern of corticosterone secretion in free-living fledglings (Fig. 2). Plasma corticoste- rone levels were significantly greater in blood samples collected after 5-10 min than in samples collected within $5 \mathrm{~min}$ (MannWhitney $U$-test, $U=24, P=0.011$ ). The single sample collected after $30 \mathrm{~min}$ exhibited the highest corticosterone level.

\section{Discussion}

\section{Captive Young Western Screech-Owls}

Captive young western screech-owls of both sexes exhibited similar patterns of corticosterone secretion in response to the handling stress protocol. This is consistent with the results of earlier studies on adult birds that revealed no gender differences in the adrenocortical response in most, but not all, situations (Wingfield et al. 1992; Astheimer et al. 1994; Smith et al. 1994; Wingfield et al. 1995). Those gender differences in corticosterone secretion that do occur may be associated with parental behavior that evolved in response to unpredictable weather during the breeding season. For example, there is often an inverse relationship between the degree of parental care and maximum corticosterone levels (Wingfield et al. 1995). Parental behavior is unlikely to be developed in sexually immature birds, and this could account for the indistinguishable stress responses in young male and female screech-owls.

Although the overall pattern of secretion was similar in both periods, corticosterone levels were significantly higher during the inactive period. Thus, young screech-owls may have responded differently to handling stress in their active and inactive periods. One explanation for this phenomenon is that handling stress may be more severe when it occurs during a bird's inactive period. That is, birds that are not alert or are asleep may be more startled and alarmed, and produce a stronger adrenal response, than birds that are active and more aware of events happening around them.

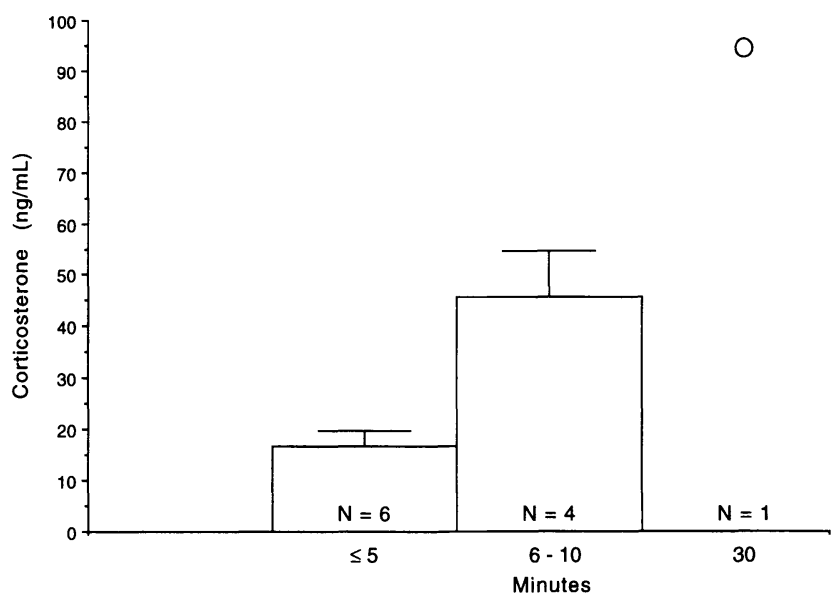

Figure 2. Circulating corticosterone levels (mean $\pm \mathrm{SE}$ ) in freeliving juvenile western screech-owls sampled after three different handling durations. Sample sizes are indicated. 
Alternatively, the difference may have resulted from a daily rhythm in corticosterone secretion. Such rhythms have been documented in diurnal species, with increased baseline corticosterone levels occurring during the inactive period (e.g., Boissin and Assenmacher 1971; Joseph and Meier 1973; Beuving and Vonder 1977). Unlike species investigated in these previous studies, screech-owls are nocturnal; thus, their inactive period is during the daytime. If the daily rhythm of corticosterone is likewise reversed, then the stronger stress response we observed during the day may simply reflect higher baseline corticosterone values at that time. Although none of the activity period $\times$ time pairwise comparisons achieved significance at the 0.05 level, the baseline (i.e., 1 -min) sample nearly did so $(P=0.0811)$, and mean daytime corticosterone values were similarly elevated above mean nighttime values at all sampling times. This supports the idea that while the overall pattern of adrenocortical secretion is similar in both activity periods, the baseline corticosterone levels differ.

Plasma corticosterone levels in young western screech-owls rose significantly in response to the stress protocol between the 1-, 5-, and 10-min samples and plateaued at $30 \mathrm{~min}$, which is similar to results from earlier studies (Wingfield et al. 1992; Astheimer et al. 1994; Smith et al. 1994; Wingfield et al. 1995). However, there was a significant decline in circulating corticosterone between 30 and $60 \mathrm{~min}$, which was rarely reported in previous investigations. Most of these earlier studies focused on adults, and circulating corticosterone typically peaked in the 10 - or 30 -min samples and remained elevated through the 60-min sample.

Interestingly, a reduction in corticosterone titers between the 30- and 60-min samples of the stress protocol also occurs in young captive American kestrels (Falco sparverius; J. A. Heath and A. M. Dufty, Jr., unpublished data). In addition, Freeman and Flack (1980) found that plasma corticosterone levels in 3-wk-old domestic chicks typically rise between samples obtained 0-5 min and 5-10 min after handling but then fall in samples taken at $15-20 \mathrm{~min}$ and $30-35 \mathrm{~min}$. This pattern may simply reflect incomplete development of the hypothalamo-pituitary-adrenal axis in young birds. Alternatively, any consistent differences in adrenal activity between young and adults may result from different age-related selective pressures. In adults, the adrenocortical response varies in different ecological situations in ways that enhance survival of individuals or their young (Wingfield 1994; Wingfield et al. 1995). A muted adrenocortical response in young birds also may have survival benefits. For example, it could facilitate maintenance of protein stores or reduce movements away from protective parents or out of newly acquired territories. We have not examined the stress response in adult western screech-owls, so it is not known whether the pattern of corticosterone secretion seen in young screech-owls is typical of the species or is age related.

Another potential explanation for the significant drop in corticosterone levels after $60 \mathrm{~min}$ is that the owls (and kestrels) were maintained in captivity for many weeks, handled on a daily basis, and bled at least once per week. Thus, the birds could have habituated to being handled, learned that soon they would be returned to their cages, and subsequently moderated their adrenal response to handling. It is unclear whether the domestic chicks (Freeman and Flack 1980) were handled on a regular basis, yet they exhibited a similar pattern of corticosterone secretion.

Finally, there is some evidence that body condition affects the stress response in a variety of vertebrates. For example, poorly nourished young American kestrels show no significant decrease in corticosterone between 30 and $60 \mathrm{~min}$ of the stress protocol, while well-nourished birds do (J. A. Heath and A. M. Dufty, Jr., unpublished data). Similarly, green sea turtles (Chelonia mydas) with and without fibropapillomas exhibit different responses to capture stress (Aguirre et al.

Table 1: Results of mixed factorial ANOVA on log-transformed data

\begin{tabular}{|c|c|c|c|c|}
\hline Source & $\mathrm{df}$ & Mean Squares & $F$ & $P$ \\
\hline Sex & 1 & .0474 & .17 & 688 \\
\hline Error & 9 & .2748 & & \\
\hline Activity period & 1 & .8787 & 5.47 & .044 \\
\hline Error & 9 & .1608 & & \\
\hline 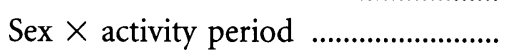 & 1 & .0095 & .06 & .813 \\
\hline 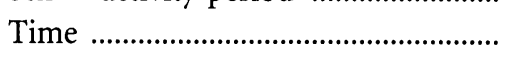 & 4 & 3.5576 & 39.51 & $<.001$ \\
\hline Error & 36 & .0900 & & \\
\hline Sex $\times$ time & 4 & .0241 & .27 & .897 \\
\hline Activity period $\times$ time & 4 & .0148 & .17 & .952 \\
\hline Error & 36 & .0864 & & \\
\hline Sex $\times$ activity period $\times$ time $\ldots \ldots \ldots \ldots$ & 4 & .0622 & .72 & .584 \\
\hline
\end{tabular}

Note. Sex was a between-groups factor, and period and time were within-subjects factors. 
1995). Thus, the fact that screech-owls in our study were fed ad lib. and were likely in excellent body condition also could have contributed to the significant decrease in corticosterone between 30 and $60 \mathrm{~min}$. Clearly, stress responses in adult and naive young birds, as well as those in well- and poorly nourished individuals, need to be examined before the reduction in corticosterone after $60 \mathrm{~min}$ in young western screechowls can be interpreted more precisely.

One juvenile male, bird 064, did not produce any stress response during the $1 \mathrm{~h}$ of handling in either the active or inactive periods (Fig. 1C). This bird showed no evidence of disease: its body weight, plumage, and behavior all appeared normal. Astheimer et al. (1994) determined that male sparrows undergoing postbreeding molt exhibit minimal increases in plasma corticosterone. However, bird 064 was engaged only in the first prebasic molt typical of the entire cohort of captive screech-owls. Hence, we cannot determine whether this bird had an immature or an abnormal hypothalamo-pituitary-adrenal axis.

\section{Free-Living Young Western Screech-Owls}

The initial increase in plasma corticosterone levels displayed by captive juvenile screech-owls was mirrored in free-living juvenile owls captured in mist nets. The two data sets were not compared statistically because of fundamental procedural differences in the timing of sample collection and the number of samples obtained. Nonetheless, corticosterone values for free-living birds sampled in $5 \mathrm{~min}$ or less and 5-10 min after capture are similar to, albeit slightly higher than, those found in captive owls over the first $10 \mathrm{~min}$ of the handling stress protocol. The highest plasma corticosterone value from free living young owls was measured in the single sample obtained $30 \mathrm{~min}$ after capture. Although this value was more than twice the corresponding mean value for captive owls, it coincided with the period of peak corticosterone levels in the captiv $\rightarrow$ birds.

Finally, the similarity between basal corticosterone levels measured in captive owls (the initial stress protocol sample $\rightarrow$ and free-living owls (the samples obtained in $\leq 5 \mathrm{~min}$ ) contrasts with the results of Marra et al. (1995), who found that captive sparrows manifest significantly higher basal plasma corticosterone levels throughout the day than do free-living spar rows. It is possible that the owls maintained in captivity for more than 3 mo had adequate time to adjust to captive conditions, whereas the sparrows (35-d captivity) did not.

\section{Conclusion}

In summary, our results demonstrate that young western screech-owls exhibit an adrenocortical response to handling stress that is similar in both sexes. Furthermore, by using a nocturnal species, we have uncoupled the active/inactive peri- ods from the light/dark cycle. Circulating corticosterone levels were higher during the owls' inactive (daytime) period, which suggests that peaks in the diurnal rhythm of corticosterone are associated with the species' daily activity pattern rather than with the photoperiod. In addition, unlike the results from many previous studies, mean corticosterone levels in young owls declined 30-60 min after capture. We suggest that this may reflect age-related differences in the stress response, acclimation to captivity and handling, or an effect of body condition. Finally, the results obtained from captive owls appear to be similar to those from free-living juvenile screech-owls.

\section{Acknowledgments}

We thank L. Belthoff, J. Doremus, B. and C. Dufty, E. and M. Ellsworth, J. Emerson, J. Heath, D. Lowe, and S. Mitchell for assistance in the laboratory and field. We gratefully acknowledge the financial support of the Idaho State Board of Education (specific research grant S95-042), the National Science Foundation (award IBN-9509079), and Boise State University (faculty research grant and faculty research associateship). We also thank the Boise District of the U.S. Bureau of Land Management, the Snake River Birds of Prey National Conservation Area, and particularly J. Doremus for facilitating our fieldwork on owls. We collected young owls under a U.S. Fish and Wildlife Service permit (PRT 785053) and a State of Idaho Department of Fish and Game scientific collecting permit (SCP 930810).

\section{Literature Cited}

Aguirre A.A., G.H. Balazs, T.R. Spraker, and T.S. Gross. 1995. Adrenal and hematological responses to stress in juvenile green turtles (Chelonia mydas) with and without fibropapillomas. Physiol. Zool. 68:831-854.

Astheimer L.B., W.A. Buttemer, and J.C. Wingfield. 1992. Interactions of corticosterone with feeding, activity and metabolism in passerine birds. Ornis Scand. 23:355-365.

$\rightarrow-1994$. Gender and seasonal differences in the adrenocortical response to ACTH challenge in an Arctic passerine, Zonotrichia leucophrys gambelii. Gen. Comp. Endocrinol. 94:33-43.

Belthoff J.R. and A.M. Dufty, Jr. 1995. Locomotor activity levels and the dispersal of western screech-owls, Otus kennicottii. Anim. Behav. 50:558-561.

$\rightarrow$ Belthoff J.R. and G. Ritchison. 1989. Natal dispersal of eastern screech-owls. Condor 91:254-265.

$\rightarrow-$ 1990. Roosting behavior of postfledging eastern screech-owls. Auk 107:567-579.

Beuving G. and G.M. Vonder. 1977. Daily rhythm of corticosterone in laying hens and the influence of egg laying. J. Reprod. Fertil. 51:169-173.

Boissin J. and I. Assenmacher. 1971. Entrainment of the adrenal 
cortical rhythm and of the locomotor activity rhythm by ahemeral photoperiods in the quail. J. Interdisciplinary Cycle Res. 2:437-443.

Buttemer W.A., L.B. Astheimer, and J.C. Wingfield. 1991. The effect of corticosterone on standard metabolic rates of small passerine birds. J. Comp. Physiol. 161B:427-431.

$\rightarrow$ Cherel Y., J.-P. Robin, and Y. Le Maho. 1988. Physiology and biochemistry of long-term fasting in birds. Can. J. Zool. 66:159-166.

$\rightarrow$ Freeman B.M. and I.H. Flack. 1980. Effects of handling on plasma corticosterone concentrations in the immature domestic fowl. Comp. Biochem. Physiol. 66A:77-81.

$\rightarrow$ Gray J.M., D. Yarian, and M. Ramenofsky. 1990. Corticosterone, foraging behavior, and metabolism in dark-eyed juncos, Junco hyemalis. Gen. Comp. Endocrinol. 79:375384.

$\rightarrow$ Harvey S., J.G. Phillips, A. Rees, and T.R. Hall. 1984. Stress and adrenal function. J. Exp. Zool. 232:633-645.

Johnsgard P.A. 1988. North American Owls: Biology and Natural History. Smithsonian Institution Press, Washington, D.C.

$\rightarrow$ Joseph M.M. and A.H. Meier. 1973. Daily rhythms of plasm: corticosterone in the common pigeon, Columba livia. Gen. Comp. Endocrinol. 20:326-330.

$\rightarrow$ Marra P.P., K.T. Lampe, and B.L. Tedford. 1995. Plasma corticosterone levels in two species of Zonotrichia sparrows under captive and free-living conditions. Wilson Bull. 107:296305.

$\rightarrow$ Ritchison G., J.R. Belthoff, and E.J. Sparks. 1992. Dispersal restlessness: evidence for innate dispersal by young eastern screech-owls? Anim. Behav. 43:57-65.

$\rightarrow$ Smith G.T., J.C. Wingfield, and R.R. Veit. 1994. Adrenocortical response to stress in the common diving petrel, Pelecanoides urinatrix. Physiol. Zool. 67:526-537.

Webb M.L. and M.M. Mashaly. 1985. Maturation of the dirunal rhythm of corticosterone in female domestic fowl. Poult. Sci. 64:744-750.

Wingfield J.C. 1984. Effects of weather on reproduction. J. Exp. Zool. 232:589-594.

1994. Modulation of the adrenocortical response to stress in birds. Pp. 520-528 in K.G. Davey, R.E. Peter, and S.S. Tobe, eds. Perspectives in Comparative Endocrinology. National Research Council of Canada, Ottawa.

$\rightarrow$ Wingfield J.C., K.M. O’Reilly, and L.B. Astheimer. 1995. Modulation of the adrenocortical responses to acute stress in Arctic birds: a possible ecological basis. Am. Zool. 35:285-294.

Wingfield J.C., C.M. Vleck, and M.C. Moore. 1992. Seasonal changes of the adrenocortical response to stress in birds of the Sonoran Desert. J. Exp. Zool. 264:419-428.

Zolman J.F. 1993. Biostatistics: Experimental Design and Statistical Inference. Oxford University Press, New York. 